\title{
ALTERAÇÕES HISTOPATOLÓGICAS
}

E MACROSCÓPICAS EM UM CÃO

SOROLOGICAMENTE POSITIVO PARA Leptospira spp.

\section{Dayane Olimpia Gomes ${ }^{1}$, Gabriela Bim Ramos ${ }^{1}$, Andreia Zago Ciuffa ${ }^{1}$, Silvia Cassimiro Brasão ${ }^{1}$, Anna Monteiro Correia Lima ${ }^{1}$, Nicolle Pereira Soares ${ }^{2}$, Matias Pablo Juan Szabó e Danilo Mundim Silva ${ }^{1}$ \\ RESUMO}

\begin{abstract}
A leptospirose é uma zoonose de distribuição mundial com elevada incidência em regiões tropicais. Nos cães ela se apresenta com grande polimorfismo clínico e estes animais são considerados fonte de infecção da leptospirose humana, mesmo quando não apresentam qualquer sinal clínico característico. O processo de patogênese é caracterizado pelo desenvolvimento de vasculite, lesão endotelial e infiltrado inflamatório composto por células monocíticas, plasmócitos, histiócitos e neutrófilos. O objetivo deste estudo foi relatar o caso de um cão sorologicamente positivo para leptospirose. Logo após o óbito, o animal foi encaminhado ao Departamento de Patologia Animal do Hospital Veterinário da Universidade Federal de Uberlândia. Na necropsia foram diagnosticadas icterícia hemolítica e nefrite intersticial crônica moderada. As alterações macroscópicas, histológicas e sorológicas do animal foram sugestivas de doença hemolítica grave compatível com leptospirose.
\end{abstract}

DESCRITORES: Leptospirose; Canis familiaris; sorovar; zoonose.

\section{ABSTRACT}

Case report: Macroscopic and histopathological changes in a dog serologically positive for Leptospira spp.

Leptospirosis is a zoonosis of worldwide distribution with high incidence in tropical regions. Leptospirosis in dogs presents with large clinical polymorphism and these animals are considered sources of infection for human leptospirosis, even without showing any clinical signs. Pathogenesis is characterized by the development of vasculitis, endothelial injury and infiltration of monocytic cells, plasma cells, histiocytes and neutrophils. The objective of this study was to report the case of a dog serologically positive for leptospirosis. The animal died and then was submitted to the Animal Pathology Department of the Veterinary Hospital of the Federal University of Uberlândia.

1 Laboratório de Doenças Infecto-contagiosas, Faculdade de Medicina Veterinária(por extenso), (por extenso)Universidade Federal de Uberlândia (UFU), Uberlândia, MG Brasil.

2 Laboratório de Patologia Animal, Faculdade de Medicina Veterinária, UFU,niversidade Federal de Uberlândia, MG, Brasil.

Endereço para correspondência: gabivetufu@yahoo.com.br

Recebido para publicação em: 9/12/2014. Revisto em: 19/3/2015. Aceito em: 4/5/2015. 
At necropsy hemolytic jaundice and moderate chronic interstitial nephritis were diagnosed. The macroscopic, histological and serological changes suggest severe hemolytic disease consistent with leptospirosis.

KEYWORDS: Leptospirosis; Canis familiaris; pyrogenes; tarassovi; zoonosis.

\section{INTRODUÇÃO}

A leptospirose é uma doença de caráter zoonótico, amplamente distribuída no mundo todo, tendo sido descrita em todos os tipos de vertebrados, especialmente nos cães (Mello \& Manhosos, 2007), caracterizando um problema econômico e de saúde pública (Azevedo et al., 2011).

Quando clínica, pode variar de subaguda, aguda a crônica (Sykes et al., 2011). Na fase inicial, ocorre bacteremia seguida de alojamento de leptospiras, sobretudo no fígado, baço e nosrins, podendo o hospedeiro eliminar a bactéria no ambiente (Greene et al., 2006).

O contato direto com o ser humano faz com que o cão seja uma das principais fontes de transmissão da leptospirose, especialmente em ambiente urbano (Magalhães et al., 2006). Estes animais são susceptíveis a todos os sorogrupos de Leptospira spp. conhecidos.

Os sorotipos Canicola e Icterohaemorrhagiae são tradicionalmente associados à doença (Oliveira, 2010), porém estudos como o de Querino et al. (2003) e Castro et al. (2011) demonstraram que a ocorrência desses sorotipos clássicos vem decrescendo, enquanto cresce a de outros sorovares, como Pyrogenes e Tarassovi, semanifestado. O sorovar Pyrogenes é um dos mais patogênicos para o homem, com repercussão na saúde pública (Stanchi \& Arias, 1997).

A determinação do sorovar é essencial para a investigação clínica e epidemiológica da doença, visto que pode indicar o reservatório envolvido na transmissão e, consequentemente, a melhor forma para seu controle e prevenção (Ko et al., 2009).

O objetivo do presente trabalho foi relatar o caso de um cão sorologicamente positivo para sorovares acidentais de Leptospira spp. e suas alterações histopatológicas e macroscópicas.

\section{RELATO DE CASO}

O cadáver de um cão adulto da raça Fila Brasileiro, domiciliado na zona urbana e com histórico de vacinação desconhecido, foi encaminhado logo após o óbito ao Departamento de Patologia Animal do Hospital Veterinário da Universidade Federal de Uberlândia. A suspeita da causa mortis era envenenamento e, para confirmação, a proprietária requisitou a necropsia.

A coleta de $5 \mathrm{~mL}$ de sangue foi feita por meio de punção cardíaca (Hoff \& Rlagt, 2000), com seringa de $10 \mathrm{~mL}$ e agulha de $25 \times 8 \mathrm{~mm}$ esterilizada. A amostra foi 
acondicionada em frasco sem anticoagulante e enviada ao Laboratório de Doenças Infectocontagiosas da Universidade Federal de Uberlândia, onde foi centrifugada a $3000 \mathrm{~g}$ por 5 minutos para obtenção do soro e posterior realização da soroaglutinação microscópica (SAM), considerada o exame padrão ouro pela Organização Mundial da Saúde para o diagnóstico de leptospirose (OIE, 2012).

Foram testados 14 sorovares de Leptospira interrogans: Autumnalis, Australis, Bataviae, Bratislava, Canicola, Copenhageni, Grippotyphosa, Hardjo, Hebdomadis, Icterohaemorrhagiae, Pomona, Pyrogenes, Tarassovi e Wolffi. Nos testes, o cão foi sororreagente para Pyrogenes e Tarassovi, em titulações de 1/400 e $1 / 800$, respectivamente.

No exame macroscópico, foram relatadas as seguintes alterações: mucosas ocular e oral ictéricas (Figura1); tecido subcutâneo da região abdominal ictérico; rins aumentados de volume com áreas enegrecidas na superfície que aprofundavam ao corte (Figura 2); baço pálido, friável com áreas amareladas multifocais na superfície, aumentado de volume, bordas abauladas e parênquima amolecido (Figura 4); cérebro com vasos repletos de sangue (Figura 5). Foram coletados fragmentos de rim, fígado, baço, cérebro e cerebelo, acondicionados em formol 10\% tamponado para exame histopatológico.

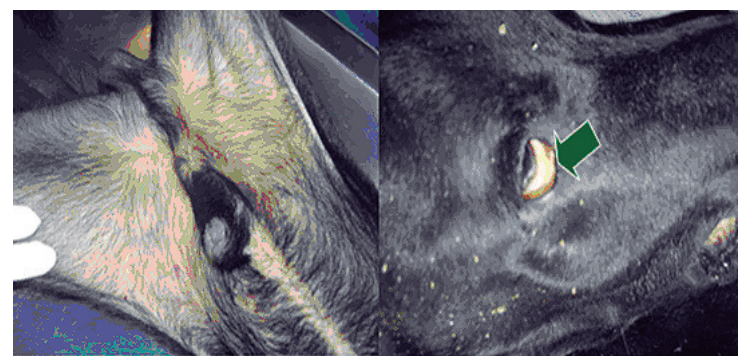

Figura 1. Cão Fila Brasileiro adulto com pele de virilhas e mucosa ocular (seta) ictéricas.

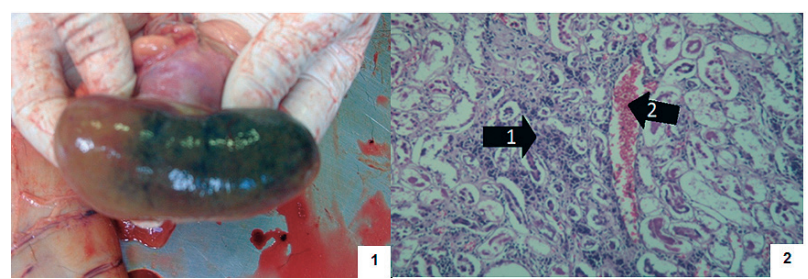

Figura 2. Cão Fila Brasileiro adulto. Imagem 1. Macroscopia de rim aumentado de volume, com áreas enegrecidas na superfície. Imagem 2. Fotomicrografia de rim apresentando infiltrado inflamatório intersticial (seta 1) e hiperemia passiva (seta 2), microscopia óptica (MO), 40x, hematoxilina e eosina (HE). 
$\mathrm{Na}$ análise histopatológica, foram descritas as seguintes lesões: rim material em autólise avançada, vasos repletos de hemácias (hiperemia), infiltrado inflamatório moderado linfoplasmocitário multifocal no interstício (Figura 2); fígado (Figura 3) - material em autólise avançada e perda da arquitetura hepática, sinusoides repletos de hemácias (hiperemia passiva), grânulos marrons em canalículos biliares (colestase); baço (Figura 4) - grânulos marrons em citoplasma de macrófagos (hemossiderina); cérebro (Figura 5) - material em autólise avançada e vasos repletos de hemácias (hiperemia).

As alterações sorológicas, macroscópicas e histológicas relatadas neste estudo direcionam ao diagnóstico conclusivo de doença hemolítica grave, compatível com leptospirose.

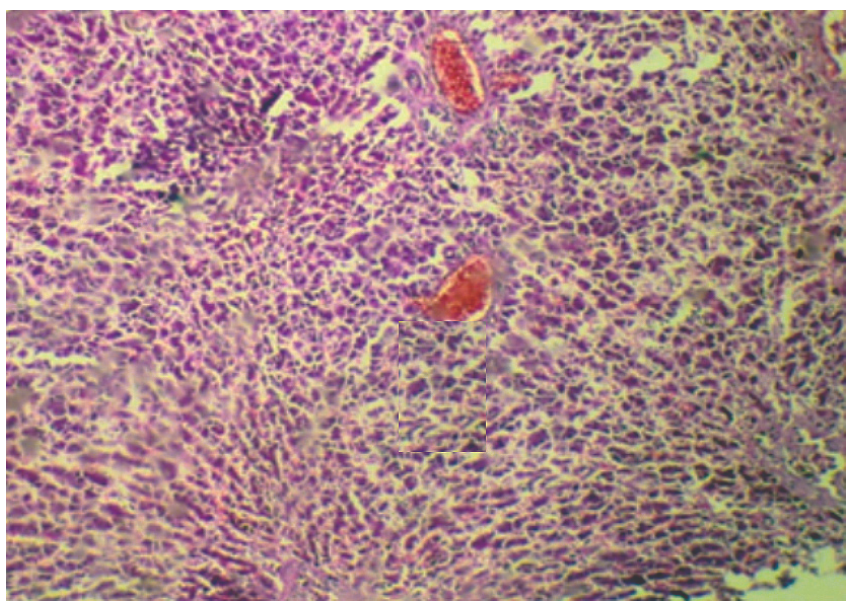

Figura 3. Cão Fila Brasileiro adulto. Fotomicrografia de corte histológico de fígado. Notar (seta) sinusoides repletos de hemácias (hiperemia passiva), MO, 10x, HE.
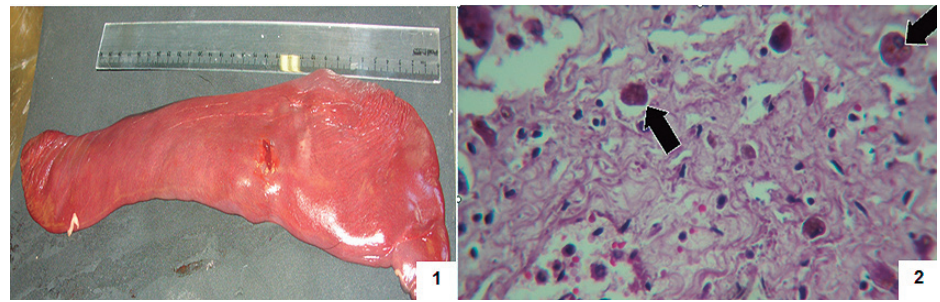

Figura 4. Cão Fila Brasileiro adulto. Imagem 1. Macroscopia de baço pálido, aumentado de volume e bordas abauladas. Imagem 2. Fotomicrografia de baço, Macrógafos (setas) apresentam hemossiderina citoplasmática,40x, HE. 


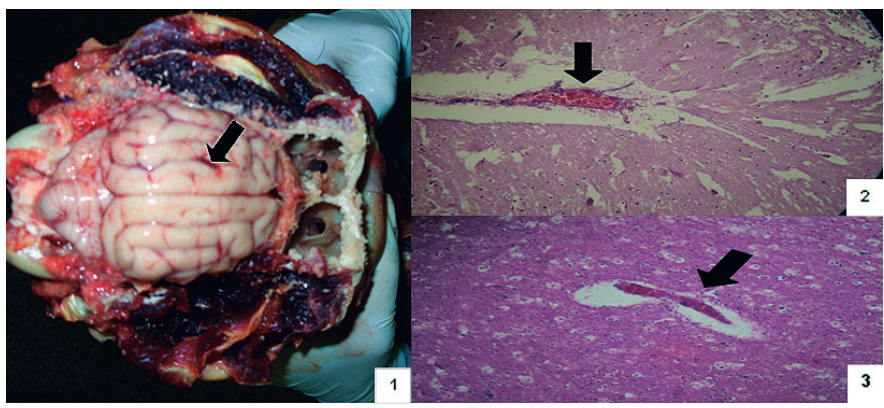

Figura 5. Cão Fila Brasileiro adulto. Imagem 1. Macroscopia de encéfalo. Notar (seta) vasos repletos de sangue (hiperemia). Imagens 2 e 3. Fotomicrografias de cérebro e cerebelo, respectivamente, que apresentam vasos repletos de hemácias (setas), caracterizando hiperemia passiva, MO, 10x, HE.

\section{DISCUSSÃO}

Este relato evidencia a presença de reações sorológicas próprias dos sorovares Pyrogenes e Tarassovi, considerados acidentais para cães. Similarmente, um estudo realizado em Londrina-PR verificou a soroprevalência de 51,0\% em 160 amostras testadas, com predomínio do sorovar Pyrogenes (Querino et al., 2003).

Modolo et al. (2000) encontraram 34,5\% cães reagentes para Pyrogenes na cidade de Botucatu-SP. Em cães domiciliados no município de Uberlândia-MG, os sorovares mais frequentes foram Autumnalis (34,2\%) e Tarassovi (23,7\%). Acredita-se, portanto, que a vacinação contra leptospirose tornou-se efetiva a ponto de provocar a redução de casos da doença quando causada pelos sorovares Icterohemorrhagiae e Canicola, que são os principais encontrados nas vacinas comerciais. Por outro lado, surgem novas formas de apresentação da doença causadas por outros sorovares (Castro et al., 2011).

No Brasil, o sorovar Pyrogenes foi primeiramente isolado de mamífero silvestre (Nectomys squamipes) por Santa Rosa et al. (1980), em áreas próximas à cidade de São Paulo, e também detectado sorologicamente em cães de outras localidades (Furtado et al., 1997; Jouglard \& Brod, 2000; Querino et al., 2003; Magalhães et al., 2006).

Inquéritos sorológicos mostram a participação de vários sorovares na infecção leptospírica canina (Langoni et al., 2013). Os cães podem infectar-se quando em contato com a urina contaminada de outros animais domésticos, de produção ou silvestres (Greene, 2006). Assim, justifica-se o encontro, aqui relatado, do sorovar Tarassovi, que tem como hospedeiro definitivo os suínos (Ellis, 2006).

Os resultados do presente estudo, somados aos da literatura, enfatizam a importância dos animais silvestres como reservatórios de leptospiras e como fontes 
de contágio para cães e para o homem. Isso salienta o aparecimento de sorovares pouco frequentes em cães doentes ou que foram a óbito e mostra a importância da realização de inquéritos sorológicos como ações de vigilância contínua para que sejam adotadas medidas de prevenção e tratamento adequado.

Em relação às alterações anatomopatológicas, muitos autores caracterizam a leptospirose por icterícia, hemorragia e uremia (Tochetto et al., 2012). A infecção aguda pode levar o animal à morte rapidamente, sem o aparecimento prévio de sinais clínicos (Greene et al., 1998). Nesta forma pode ocorrer disfunção da coagulação, o que leva ao quadro de coagulação intravascular disseminada (CID) e a bacteremia pode resultar em sepse e morte (Sykes et al., 2011), corroborando os achados e descritos neste relato.

Já os autores Searcy (1988), Center et al. (1990) e Lappin (1992) relatam a leptospirose como uma doença que cursa com algum grau de lesão hepática, vascular e renal, o que justifica as alterações anatomopatológicas do caso relatado. A colonização dos rins pelos microrganismos causa insuficiência renal. Esta infecção provoca edema do tecido renal comprometendo seu aporte sanguíneo e culminando na redução da taxa de filtração glomerular, hipóxia e falência renal aguda (Langston $\&$ Heuter, 2003).

Não são conhecidos totalmente os fatores responsáveis pela virulência da Leptospira, no entanto os achados clínicos e histológicos sugerem ser a endotoxina a principal causa de danos. Alguns sorovares têm capacidade de produzir hemolisina em quantidade suficiente para provocar intensa hemólise intravascular, resultando em hemoglobinúria. Proteínas citotóxicas também são produzidas por alguns exemplares virulentos, porém não se conhece a atuação destas toxinas. Esfingomielinases e porinas também podem ser expressas por alguns sorovares. Esstas toxinas podem causar vasculite com graves danos endoteliais (Lima, 2013).

As alterações macroscópicas observadas neste relato de caso foram descritas por Tochetto et al. (2012) em uma revisão de 53 casos clínicos de leptospirose. Segundo os autores, 79,2\% dos casos apresentavam icterícia; 75,5\%, algum grau de hemorragia; $56,6 \%$, alterações no fígado; $50,9 \%$, alterações renais; $41,5 \%$, edema pulmonar e $26,4 \%$, edema pulmonar e hemorragia, concomitantemente.

Chandrasekaran et al. (2011) realizaram exames post mortem em dez cães que morreram durante o tratamento para leptospirose canina. Eles encontraram os seguintes resultados: nos rins - necrose tubular com infiltração intersticial linfoplasmocitária e de neutrófilos; no fígado - marcada congestão dos sinusoides em sete cães (70\%), alterações degenerativas em cinco cães (50\%), hiperplasia do ducto biliar com áreas de infiltrações multifocais de células em cinco cães (50\%) e um caso $(10 \%)$ de cirrose periportal. As alterações histológicas renais e hepáticas encontradas pelos autores são semelhantes às descritas neste trabalho.

A suspeita de envenenamento do cão citada neste estudo foi descartada, visto que não foram encontrados achados patológicos como hemorragias sistêmicas, 
congestão de diferentes órgãos e edema pulmonar, indicativos de envenenamento (Emmel et al., 2006). Na prática clínica, os cães que desenvolvem sinais de insuficiência renal aguda e/ou icterícia devem ser considerados como casos suspeitos de leptospirose até que haja um diagnóstico definitivo (Maele et al., 2008).

Conclui-se, portanto, que definiram o diagnóstico da doença as alterações macroscópicas e histológicas indicativas de leptospirose e, sobretudo, o resultado positivo do teste de Soroaglutinação Microscópica para os sorovares Pyrogenes e Tarassovi.

\section{REFERÊNCIAS}

1. Azevedo SS, Fernandes ARF, Queiroga, IMBN, Alves CJ, Morais ZM, Santos CSAB, Vasconcellos SA. Ocorrência e fatores de risco associados à leptospirose em cães atendidos em hospital veterinário no semiárido paraibano. Braz J Vet Res Anim Sci 48:161-166, 2011.

2. Castro JR, Souza MA, Salaberry SRS, Lima-Ribeiro AMC. Sorovares de Leptospira spp. predominantes em exames sorológicos de caninos e humanos no município de Uberlândia, Estado de Minas Gerais. Rev Soc Bras Med Trop 44: 217-222, 2011.

3. Center AS, Hornbucale WE, Hoskins JD. O fígado e o pâncreas. In: Hoskins JD. Pediatria Veterinária: cães e gatos até seis meses de idade. São Paulo, Manole, 1990. p.223-270.

4. Chandrasekaran D, Prathaban S, Dhanabalan P, Balachandran C, Murali MB, Venkataraman KS. Pathological Changes in Canine Leptospirosis. Tamil Nadu J Veterinary \& Animal Sciences 7: 180-183, 2011.

5. Ellis WA. Leptospirosis. In: Straw BE, D'Allaire S, Mengeling WL, Taylor DJ, Leman AD. Diseases of swine. 9 ed. Ames: Blackwell, Iowa, 2006. p. 691-700.

6. Emmel EE, Oliveira EC, Wolffenbüttel A, Teixeira EM, Sonne L, Driemeier D. Avaliação patológica e toxicológica de cães e gatos necropsiados pelo setor de Patologia Veterinária da UFRGS. In: Salão de Iniciação Científica, 18, Porto Alegre. Anais... Porto Alegre: UFRGS, 2006. p.167.

7. Furtado LRI, Fehlberg MFB, Ávila MO, Teixeira MM, Rosado RLI, Martins LFS, Brod CS. Prevalência e avaliação de fatores de risco a leptospirose canina no município de Pelotas, RS. Arq Inst Biol 64: 57-61, 1997.

8. Greene CE, Miller MA, Brow CA. Leptospirosis. In: Greene CE. Infectious diseases of the dog and cat. 2 ed. Philadelphia, Saunders, 1998. p.273-281.

9. Greene CE, Sykes JE, Brown CA, Hartmann K. Leptospirosis. In: Greene CE. Infectious Diseases of the Dog and Cat. 3 ed. Philadelphia, Saunders ,2006. p. 402-417.

10. Hoff J, Rlagt LV. Methods of blood collection in the mouse. Laboratory animal 29: 47-53, 2000.

11. Jouglard SDD, Brod CS. Leptospirose em cães: Prevalência e fatores de risco no meio rural do município de Pelotas, RS. Arq Inst Biol 67: 181-185, 2000.

12. Ko AI, Goarant C, Picardeau M. Leptospira: the dawn of the molecular genetics era for an emerging zoonotic pathogen. Nat Rev Microbial 7: 736-747, 2009.

13. Langoni H, Silva AV, Segismundo R, Lucheis SB, Paes AC. Variáveis epidemiológicas e alterações clínicas, hematológicas e urinárias em cães sororreagentes para Leptospira spp. Semina: Ciências Agrárias 34: 765-776, 2013.

14. Langston CE, Heuter KJ. Leptospirosis. A re-emerging zoonotic disease. Veterinary Clinics of North America: Small Animal Practice 33: 791-807, 2003.

15. Lappin MR. Doenças bacterianas polissistêmicas. In: Nelson RW, Couto CG. Medicina Interna de Pequenos Animais. Rio de Janeiro, Guanabara Koogan, 1992. p.1000-1005.

16. Lima EV. Leptospirose canina: revisão bibliográfica. Monografia (Bacharelado em Medicina Veterinária). Universidade de Brasília, Brasília, 2013. 40 p. 
17. Maele IV, Claus A, Haesebroukc F, Daminet S. Leptospirosis in dogs: a review with emphasis on clinical aspects. Veterinary Record 163: 409-413, 2008.

18. Magalhães DF, Silva JA, Moreira EC, Wilke VML, Haddad JPA, Meneses JNC. Prevalência de aglutininas anti-Leptospira interrogans em cães de Belo Horizonte, Minas Gerais, 2001 a 2002. Arq Bras Med Vet Zootec 58: 167-174, 2006.

19. Mello LPP, Manhosos FFR. Aspectos epidemiológicos da leptospirose canina no Brasil. Unimar Ciências, Marília 16: 27-32, 2007.

20. Modolo JR, Langoni H, Shimabukuro FH. Inquérito soroepidemiológico para leptospirose canina, no município de Botucatu, SP. In: Congresso Brasileiro de Veterinária, 27, 2000, Águas de Lindóia. Anais...Águas de Lindóia, 2000. p.95.

21. OIE. Leptospirosis. In: Manual of diagnostic tests and vacines for terrestrial animals. World Organization for Animal Health, Paris, 2012. Disponível em: http:/www.oie.int/fileadmin/Home/ eng/Health_standards/tahm/2.01.09_LEPTO.pdf. Acesso em: 10 de março de 2015.

22. Oliveira ST. Leptospirose canina: dādos clínicos laboratoriais e terapêuticos em cães naturalmente infectados. Tese (Doutorado), Porto Alegre, UFRGS, 2010.

23. Querino AMV, Delbem ACB, Oliveira RC, Silva FG, Muller EE, Freire RL, Freitas JC. Fatores de risco associados à leptospirose em cães do município de Londrina-PR. Semina: Ciências Agrárias 24: 27-34, 2003

24. Santa Rosa CA, Sulzer C, Yanaguita RM, Da Silva AS. Leptospirosis in wildlife in Brazil: Isolation of serovars Canicola, Pyrogenes and Grippotyphosa. Int J Zoonoses 7: 40-43, 1980.

25. Searcy GP. Hematopoietic system. In: Thomson RG. Special Veterinary Pathology. Toronto: Decker, 1988. p.269-310.

26. Stanchi NO, Arias DO. Consideraciones de la leptospirosis. Avances en Medicina Veterinaria 1: 20-21,1997.

27. Sykes JE, Hartmann K, Lunn KF, Moore GE, Stoddard RA, Goldstein RE: ACVIM Small animal consensus statement on leptospirosis: diagnosis, epidemiology, treatment, and prevention. $J$ Vet Int Med 25: 1-13, 2011.

28. Thochetto C, Flores MM, Kommers GD, Barros CSL, Fighera RA. Aspectos anatomopatológicos da leptospirose em cães: 53 casos (1965-2011). Pesq Vet Bras 32: 430-443, 2012. 